\title{
Prediksi Indeks Saham Syariah Indonesia Menggunakan Model Hidden Markov
}

\author{
Risa Septi Pratiwi dan Daryono Budi Utomo \\ Departemen Matematika, Fakultas Matematka dan Ilmu Pengetahuan Alam, Institut Teknologi Sepuluh Nopember \\ (ITS) \\ e-mail: daryono.math@gmail.com
}

\begin{abstract}
Abstrak-Indeks Saham Syariah Indonesia (ISSI) merupakan indikator pergerakan harga dari keseluruhan saham syariah yang tercatat di BEI. Dalam Tugas Akhir ini ISSI diprediksi menggunakan Model Hidden Markov dengan data yang dipakai adalah periode bulan Januari 2016 sampai Maret 2017. Data selisih indeks saham dibagi menjadi beberapa state yaitu 3, 4, 5, 6 , 7, dan 8 state. Berdasarkan hasil analisis pada pembagian 4 dan 5 state nilai prediksi memiliki kecocokan $100 \%$, sedangkan pada pembagian 3 dan 6 state nilai prediksi memiliki kecocokan sebesar $80 \%$. Prediksi ISSI hanya dapat dilakukan sampai 6 state karena pada 7 dan 8 state tidak memenuhi karakteristik Model Hidden Markov.
\end{abstract}

Kata Kunci-Indeks Saham Syariah Indonesia (ISSI), Model Hidden Markov, Prediksi.

\section{PENDAHULUAN}

$\mathrm{S}$ AHAM adalah surat berharga yang menunjukkan kepemilikan modal dalam suatu perusahaan. Berdasarkan kepemilikan tersebut, pemegang saham berhak untuk mendapatkan bagian hasil dari usaha yang dikelola perusahaan serta menanggung resiko sebesar saham yang dimiliki jika perusahaan mengalami kerugian atau bangkrut. Saham syariah merupakan saham yang diperjual belikan di Pasar Modal Syariah. Pasar Modal Syariah merupakan bagian dari Industri Pasar Modal Indonesia. Secara umum, kegiatan pasar modal syariah sejalan dengan pasar modal pada umumnya. Namun terdapat beberapa karakteristik khusus pasar modal syariah yaitu bahwa produk dan mekanisme transaksi tidak boleh bertentangan dengan prinsip syariah di pasar modal.

Harga saham merupakan hal penting yang harus diperhatikan oleh investor ketika akan berinvestasi. Pergerakan naik turunnya harga saham menjadi pertimbangan dalam berinvestasi. Jika harga saham cenderung naik, investor akan tertarik untuk membeli saham. Prediksi indeks saham memberikan solusi bagi para investor untuk menentukan keputusan dalam membeli saham. Pergerakan indeks saham menggambarkan kondisi pasar modal kedepannya.

Di Indonesia terdapat dua indeks saham syariah yang merupakan indikator pergerakan indeks harga saham syariah di Bursa Efek Indonesia (BEI), yaitu Indeks Saham Syariah Indonesia (ISSI) dan Jakarta Islamic Index (JII). Dalam penulisan Tugas Akhir ini hanya difokuskan pada ISSI. ISSI merupakan indikator pergerakan harga dari seluruh saham syariah yang tercatat di Bursa Efek Indonesia (BEI), sedangkan JII merupakan bagian atau subset dari ISSI karena hanya mencakup 30 saham syariah di BEI. Saat ini jumlah konstituen ISSI yang tergabung pada Daftar Efek Syariah
(DES) dan tercatat di Bursa Efek Indonesia (BEI) sebanyak 331 saham. Konstituen ISSI akan selalu dikaji ulang dan diperbarui setiap 6 bulan sekali yaitu pada bulan Mei dan November dan dipublikasikan pada awal bulan berikutnya [1].

Salah satu model yang dapat digunakan dalam memprediksi Indeks Saham Syariah Indonesia (ISSI) adalah Model Hidden Markov. Model Hidden Markov merupakan perkembangan dari rantai Markov dengan keadaan pada masa yang akan datang dari suatu urutan tidak hanya ditentukan oleh keadaan saat ini, tetapi juga perpindahan dari suatu urutan state ke urutan state yang lainnya. Urutan state inilah yang merupakan suatu bagian yang tersembunyi dari suatu Model Hidden Markov [2]. Pendekatan prediksi data indeks saham syariah dengan memperhatikan urutan pengamatan yang tersedia ini kemudian diaplikasikan menjadi salah satu implementasi Model Hidden Markov.

Berdasarkan latar belakang tersebut, dalam penulisan Tugas Akhir ini dibahas mengenai prediksi ISSI menggunakan Model Hidden Markov. Dengan data ISSI yang diambil adalah data harian indeks penutupan (close index) pada periode bulan Januari 2016 sampai dengan Maret 2017 yang bersumber dari Burse Efek Indonesia (BEI).

\section{DASAR TEORI}

\section{A. Model Hidden Markov}

Model Hidden Markov merupakan model yang menggabungkan dua atau lebih rantai Markov dengan hanya satu rantai yang terdiri dari state yang dapat diobservasi dan rantai lainnya membentuk state yang tidak dapat diobservasi (hidden). Dalam model Markov biasa, setiap keadaan dapat terlihat langsung oleh pengamat. Oleh karena itu, kemungkinan dari transisi antar kondisi menjadi satu-satuya parameter teramati. Tetapi terkadang ada urutan dari suatu keadaan yang ingin diketahui tetapi tidak dapat diamati. Kelebihan dari Model Hidden Markov ini dapat memodelkan keadaan yang tersembunyi. Dalam Model Hidden Markov, keadaan tidak terlihat secara langsung, tetapi output yang bergantung terhadap keadaan tersebut terlihat.

Jika $X=\left\{x_{1}, x_{2}, \ldots, x_{T}\right\}$ adalah sebuah proses markov dan $O=\left\{O_{1}, O_{2}, \ldots, O_{T}\right\}$ adalah sebuah fungsi dari $X$, maka $X$ adalah sebuah Model Hidden Markov yang dapat diobservasi melalui $O$, atau dapat ditulis $O=f(X)$ untuk suatu fungsi $f$. Parameter $X$ menyatakan proses parameter-parameter yang tersembunyi, sementara parameter $O$ menyatakan proses parameter-parameter yang diamati [3]. 
Sebuah Model Hidden Markov dikarakteristikkan dengan parameter berikut:

1. $N$, banyaknya elemen keadaan tersembunyi (hidden state) pada model.

2. $M$, banyaknya elemen keadaan yang terobservasi (observable state).

3. $A=\left\{a_{i j}\right\}$, matriks peluang transisi dimana $a_{i j}$ adalah elemen dari $A$ yang merupakan peluang bersyarat dari keadaan pada saat $t+1$, jika diketahui keadaan $X$ pada saat $t$, atau $a_{i j}=P\left(X_{t+1}=j \mid X_{t}=i\right)$, dimana $1 \leq i, j \leq N$. Matriks $A$ berukuran $N \times N$ dan $a_{i j} \geq 0$ untuk setiap $1 \leq i, j \leq N$ dan $\sum_{j=1}^{N} a_{i j}=1$ untuk setiap $1 \leq i \leq N$, artinya jumlah elemen masing-masing baris adalah 1 .

4. $B=\left\{b_{i}(k)\right\}$, distribusi peluang observasi pada saat $t$ pada keadaan $i$, yang biasa dikenal dengan matriks emisi, $\quad$ dimana $b_{i}(k)=P\left(O_{t}=k \mid X_{t}=i\right), 1 \leq i \leq$ $N, 1 \leq k \leq M$. Misalkan variabel acak dari suatu keadaan terobservasi adalah $k$ dengan $k=1,2, \ldots, M$, maka matriks $B$ adalah matriks berukuran $N \times M$ dan jumlah elemen setiap baris adalah 1 .

5. $\pi=\left\{\pi_{i}\right\}, \pi_{i}=P\left(q_{1}=S_{i}\right)$, himpunan distribusi keadaan awal state.

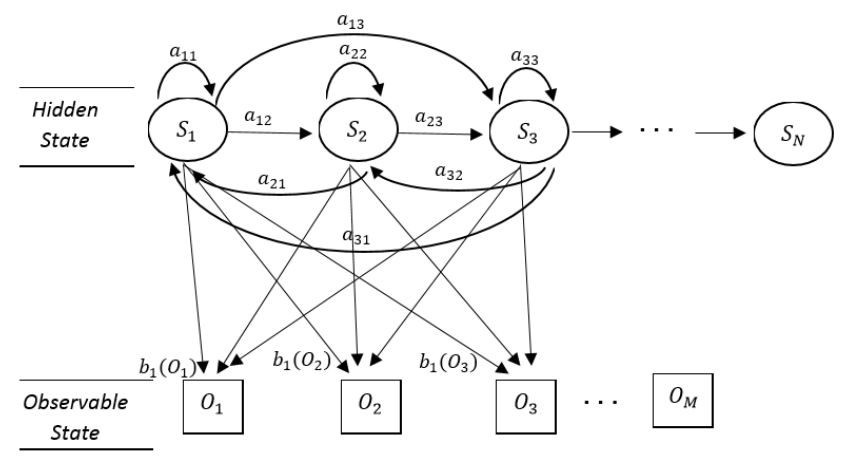

Gambar. 1. Diagram Transisi Model Hidden Markov.

Dari definisi karakteristik parameter di atas jelas bahwa dari nilai 5-tuple $(N, M, A, B$, dan $\pi)$ terdapat tiga komponen yang merupakan ukuran (probabilitas), yaitu $A, B$, dan $\pi$. Sehingga Model Hidden Markov dapat dituliskan dalam notasi $\lambda=(A, B, \pi)[4]$.

\section{B. Masalah Dasar Model Hidden Markov}

Ada tiga permasalahan khusus yang harus dipecahkan agar Model Hidden Markov dapat digunakan dalam suatu aplikasi nyata diantaranya:

\section{Evaluation Problem (Menghitung Peluang Observasi)}

Pengertian dari operasi evaluasi dalam Model Hidden Markov adalah penghitungan peluang dari urutan nilai observasi yang diberikan oleh Model Hidden Markov. Masalah ini dapat diselesaikan dengan algoritma Forward dan algoritma Backward. Pada bagian ini akan dicari peluang dari bagian observasi $(P(O \mid \lambda))$. Menurut Rabiner (1989), secara umum algoritma Forward terdiri atas tiga bagian, yaitu [5]:

- Tahap inisialisasi

$$
\alpha_{1}(i)=\pi_{i} b_{i}\left(O_{1}\right) \text { dengan } 1 \leq i \leq N
$$

- Tahap induksi

$$
\begin{gathered}
\alpha_{t+1}(j)=\left[\sum_{i=1}^{N} \alpha_{t}(i) a_{i j}\right] b_{j}\left(O_{t+1}\right) \\
\text { dengan } t=T-1, T-2, \ldots, 1,1 \leq j \leq N
\end{gathered}
$$

- Tahap terminasi

$$
P(O \mid \lambda)=\sum_{i=1}^{N} \alpha_{T}(i)
$$

Langkah algoritma Backward hampir sama dengan algoritma Forward. Namun bedanya, pada algoritma Backward inisialisasi didasarkan pada seluruh observasi yang ada. Tahap-tahap algoritma Backward dijelaskan sebagai berikut:

- Tahap inisialisasi

$$
\beta_{T}(i)=1 \text { untuk } 1 \leq i \leq N
$$

pada tahap ini dinyatakan $\beta_{T}(i)=1$ karena diasumsikan $i$ adalah state final, dan bernilai nol untuk $i$ yang lainnya.

- Tahap induksi

$$
\beta_{t}(i)=\sum_{j=1}^{N} b_{j}\left(O_{t+1}\right) \beta_{t+1}(j) a_{i j}
$$

untuk $T-1 \leq t \leq 1$ dan $1 \leq i \leq N$

- Tahap terminasi

$$
P(O \mid \lambda)=\sum_{i=1}^{N} b_{i}\left(O_{1}\right) \pi_{i} \beta_{1}(i)
$$

\section{Decoding Problem (Menentukan Barisan Keadaan \\ Tersembunyi)}

Pengertian dari decoding problem dalam Hidden Markov Model adalah penarikan kesimpulan berdasarkan asumsi yang diperoleh dari nilai probabilitas observasi yang didapat sebelumnya pada operasi evaluasi. Operasi ini juga sering kali digunakan untuk mencari nilai optimum. Masalah ini dapat diselesaikan dengan Algoritma Viterbi.

Langkah-langkah dalam algoritma Viterbi untuk menentukan barisan state terbaik yaitu [5]:

- Tahap inisialisasi

$$
\begin{gathered}
\delta_{i}(i)=\pi_{i} b_{i}\left(O_{1}\right) \text { dengan } 1 \leq i \leq N \\
\psi_{1}(i)=0
\end{gathered}
$$

- Tahap rekursi

$$
\begin{gathered}
\delta_{t}(j)=\max _{1 \leq i \leq N}\left[\delta_{t-1}(i) a_{i j}\right] \cdot b_{j}\left(O_{t}\right) \\
\text { dengan } 2 \leq t \leq T, 1 \leq j \leq N \\
\psi_{i}(i)=\arg \max _{1 \leq i \leq N}\left[\delta_{t-1}(i) a_{i j}\right] \\
\text { dengan } 2 \leq t \leq T, 1 \leq j \leq N
\end{gathered}
$$

- Tahap terminasi

$$
\begin{aligned}
P^{*} & =\max _{1 \leq i \leq N}\left[\delta_{T}(i)\right] \\
X_{T}{ }^{*} & =\arg \max _{1 \leq i \leq N}\left[\delta_{T}(i)\right]
\end{aligned}
$$

- Tahap backtracking

$$
\begin{array}{r}
X_{T}{ }^{*}=\psi_{t+1}\left(X_{t+1}^{*}\right) \\
\operatorname{dimana} t=T-1, T-2, \ldots, 1
\end{array}
$$

Learning Problem (Menaksir Parameter-Parameter Model Hidden Markov)

Pengertian dari operasi learning dalam Hidden Markov Model adalah membuat parameter-parameter baru Hidden Markov Model jika diberikan dataset barisan-barisan tertentu 
agar dapat menemukan himpunan transisi state yang paling mungkin beserta probabilitas hasilnya. Untuk menyelesaikan permasalahan learning digunakan algoritma Baum-Welch. Algoritma ini secara umum berfungsi menentukan nilai harapan dan maksimalisasi.

Langkah-langkah dalam algoritma Baum-Welch untuk menaksir parameter yaitu [5]:

- Mencari peluang proses berada pada state $i$ pada waktu $t$ dan berada pada state $j$ pada waktu $\mathrm{t}$

$$
\xi_{t}(i, j)=\frac{\alpha_{t}(i) a_{i j} b_{j}\left(O_{t+1}\right) \beta_{t+1}(j)}{P(O \mid \lambda)}
$$

- Mencari peluang proses berada pada state $i$ pada waktu $t$

$$
\gamma_{t}(i)=\sum_{j=1}^{N} \xi_{t}(i, j)
$$

- Menaksir parameter $\hat{\pi}, \hat{A}$, dan $\hat{B}$

Penghitungan parameter $\hat{\pi}, \hat{A}$, dan $\hat{B}$ dapat dihitung menggunakan persamaan:

$$
\begin{gathered}
\hat{\pi}_{i}=\gamma_{1}(i), 1 \leq i \leq N \\
\hat{a}_{i j}=\frac{\sum_{t=1}^{T-1} \xi_{t}(i, j)}{\sum_{t=1}^{T-1} \gamma_{t}(i)}, 1 \leq i \leq N, 1 \leq j \leq N \\
\hat{b}_{j}(k)=\frac{\sum_{t=1}^{T} o_{t=k} \gamma_{t}(j)}{\sum_{t=1}^{T} \gamma_{t}(j)}, 1 \leq j \leq N, 1 \leq k \leq M
\end{gathered}
$$

\section{METODE PENELITIAN}

\section{A. Menentukan Parameter Model Hidden Markov}

- Menentukan nilai $N$ (jumlah state dalam model).

- Menentukan nilai $M$ (jumlah pengamatan setiap state).

- Menentukan nilai Probability Distribution Vector $(\pi)$ atau nilai himpunan distribusi awal $\pi=[\pi(i)]$.

- Menentukan nilai Transition Probability Matrix atau matriks peluang transisi $\left(A=\left[a_{i j}\right]\right)$ yang akan menghasilkan matriks A dengan ordo $N$ x $N$.

$$
A=\left[a_{i j}\right]=\left(\begin{array}{ccc}
a_{11} & \ldots & a_{1 N} \\
: & ::: & : \\
a_{N 1} & \ldots & a_{N N}
\end{array}\right)
$$

- Menentukan nilai Emission Probability Matrix atau nilai matriks peluang bersyarat $\left(B=\left[b_{1}(k)\right]\right)$ yang akan menghasilkan matriks $B$ dengan ordo $N$ x $M$.

$$
B=\left[b_{i}(k)\right]=\left(\begin{array}{ccc}
b_{11} & \ldots & b_{1 M} \\
: & :: & : \\
b_{N 1} & \ldots & b_{N M}
\end{array}\right)
$$

\section{B. Menghitung Prediksi Parameter ISSI}

Untuk menghitung prediksi parameter ISSI dengan menggunakan Model Hidden Markov terdapat tiga langkah yang harus dilakukan yaitu:

- Menghitung peluang observasi dengan menggunakan algoritma Forward-Backward.

- Menentukan barisan keadaan tersembunyi dengan menggunakan algoritma Viterbi.

- Menaksir parameter Model Hidden Markov dengan menggunakan algoritma Baum-Welch.

\section{Simulasi}

Pada tahap ini akan dibuat simulasi dari matrik yang telah didapatkan dengan menggunakan software MATLAB. Simulasi ini digunakan untuk memprediksi indeks saham syariah.

\section{Analisis Hasil Simulasi}

Pada tahap ini dilakukan analisis dari hasil simulasi. Analisis yang dilakukan yaitu menganalisis keakuratan hasil dari prediksi dengan menggunakan Hidden Markov. Setelah didapat nilai prediksi Indeks Saham Syariah Indonesia (ISSI) maka akan dilakukan perbandingan ISSI aktual dengan ISSI hasil prediksi.

\section{ANALISIS DAN PEMBAHASAN}

\section{A. Penentuan Parameter Model Hidden Markov}

Data yang digunakan pada penelitian ini yaitu indeks penutupan (close index) ISSI dari 4 Januari 2016 sampai 31 Maret 2017 yang berjumlah 302 data. Dari data tersebut diperoleh 301 data selisih indeks saham hari ini dengan indeks saham kemarin.

Untuk menentukan parameter, terlebih dahulu data selisih indeks saham hari ini dengan indeks saham kemarin diklasifikasikan menjadi beberapa state yang berupa interval. Selanjutnya akan dibentuk matriks peluang keadaan awal, matriks transisi, dan matriks emisi.

1. Pembentukan State dan Probabilitas State

Pada bagian ini dibentuk state berupa interval dari data selisih indeks saham hari ini dengan indeks saham kemarin. Dalam Tugas Akhir ini penulis membagi data selisih indeks saham ke dalam 3, 4, 5, 6, 7, dan 8 state. Setelah itu ditentukan peluang kemunculan dari masing-masing state yaitu $\pi_{i}=\frac{s_{i}}{\text { banyak data }}, i=1,2, \ldots, N$.

Nilai maksimum dari data selisih indeks saham yang diperoleh adalah 4.536 dan nilai minimum yang diperoleh adalah (-7.665). Kemudian dicari selisih dari nilai maksimum dan nilai minimum dan dibagi menjadi 3, 4, 5, 6, 7 , dan 8 interval. Untuk pembagian 4 state diperoleh interval untuk state 1 adalah [-7.6650, -4.6147), interval untuk state 2 adalah [-4.6147, -1.5645), interval untuk state 3 adalah [$1.5645,1.4858)$, dan interval untuk state 4 adalah [1.4858, 4.5360]. Kemudian diperoleh matriks peluang keadaan awal $\pi=\left[\begin{array}{llll}0.0033 & 0.1063 & 0.7542 & 0.1362\end{array}\right]$.

\section{Pembentukan Matriks Transisi}

Pada bagian ini dihitung transisi dari masing-masing state. Transisi dari $S_{i}$ ke $S_{j}$ dilambangkan $S_{i j}$ dengan $i=1,2, \ldots, N$ $\operatorname{dan} j=1,2, \ldots, N$. Peluang transisi state didapatkan dari pembagian transisi masing-masing state, $a_{i j}=\frac{s_{i j}}{s_{i}}$. Selanjutnya dibentuk matriks probabilitas transisi. Untuk pembagian 4 state diperoleh matriks transisi sebagai berikut:

$$
A=\left[\begin{array}{cccc}
0 & 1 & 0 & 0 \\
0 & 0.1250 & 0.6250 & 0.2500 \\
0 & 0.0929 & 0.7832 & 0.1239 \\
0.0244 & 0.1463 & 0.7073 & 0.1220
\end{array}\right]
$$


3. Pembentukan Matriks Emisi

Pada bagian ini dihitung probabilitas observasi dari masingmasing state. Banyaknya observasi dari setiap state dilambangkan $S_{i}(k)$ dengan $i=1,2, \ldots, N$ dank $=$ 1 (Naik), 2 (Turun). Untuk menentukan observable state tersebut, terlebih dahulu data Indeks penutupan (close index) diklasifikasikan menjadi Naik atau $U p(\mathrm{U})$ dan Turun atau Down (D). Naik untuk nilai selisih indeks yang besarnya lebih dari nol dan Turun untuk nilai selisih indeks yang besarnya kurang dari nol.

Selanjutnya peluang observasi dari masing-masing state didapatkan dari pembagian $S_{i}(k)$ terhadap $S_{i}$ atau dapat ditulis $b_{i}(k)=\frac{s_{i}(k)}{s_{i}}$. Kemudian dibentuk matriks emisi. Untuk pembagian 4 state diperoleh matriks emisi.sebagai berikut:

$$
B=\left[\begin{array}{cc}
0 & 1 \\
0 & 1 \\
0.5110 & 0.4890 \\
1 & 0
\end{array}\right]
$$

\section{B. Penghitungan Prediksi Parameter ISSI}

Pada penelitian Tugas Akhir ini, peneliti memilih lima hari untuk diprediksi. Untuk menghitung prediksi ISSI dengan menggunakan Model Hidden Markov terdapat tiga langkah yang dilakukan yaitu penghitungan peluang observasi, penentuan barisan keadaan tersembunyi, dan penaksiran parameter ISSI.

1. Penghitungan Peluang Observasi

Permasalahan pertama yaitu penghitungan peluang observasi yang diselesaikan dengan menggunakan algoritma Forward dan algoritma Backward. Indeks saham diprediksi untuk periode 5 hari $(T=5)$, jadi terdapat $2^{5}$ atau sebanyak 32 kemungkinan observasi.

Selanjutnya dihitung peluang dari setiap kemungkinan observasi menggunakan software MATLAB. Besarnya peluang menggunakan algoritma Forward dihitung berdasarkan persamaan (1), (2), dan (3), dan besarnya peluang menggunakan algoritma Backward dihitung menggunakan pesamaan (4), (5), dan (6). Dari hasil penghitungan tersebut, peluang terbesar yang diperoleh dari pembagian 4 state adalah 0.0364 yaitu barisan observasi $O=($ naik, naik, naik, naik, naik).

\section{Penentuan Barisan Keadaan Tersembunyi}

Permasalahan kedua dalam Model Hidden Markov adalah penentuan barisan keadaan tersembunyi yang paling optimal. Permasalahan ini diselesaikan menggunakan algoritma Viterbi dengan barisan observasi yang digunakan adalah hasil algoritma Forward-Backward yaitu $O=($ naik, naik, naik, naik, naik).

Untuk menentukan barisan keadaan tersembunyi dilakukan beberapa tahap yaitu tahap inisialisasi, tahap rekursi, tahap terminasi, dan tahap backtracking. Tahap inisialisasi dihitung menggunakan persamaan (7) dan (8). Dari persamaan tersebut untuk pembagian 4 state dan $O_{1}=1$ (naik) dihasilkan

$\delta_{1}(1)=0, \delta_{1}(2)=0, \delta_{1}(3) 0.3854, \delta_{1}(4)=0.1362$

$\psi_{1}(1)=\psi_{1}(2)=\psi_{1}(3)=\psi_{1}(4)=0$

Selanjutnya pada tahap rekursi digunakan persamaan (9) dan (10). Untuk $2 \leq t \leq 5$ dan $O_{2}=1$ (naik), $O_{3}=$ 1(naik), $O_{4}=1$ (naik), dan $O_{5}=1$ (naik) diperoleh hasil sebagai berikut:

Tabel 1.

Rangkaian Terbaik 4 State

\begin{tabular}{ccccc}
\hline \hline $\mathbf{j}$ & $\boldsymbol{\delta}_{\mathbf{2}}(\boldsymbol{j})$ & $\boldsymbol{\delta}_{\mathbf{3}}(\boldsymbol{j})$ & $\boldsymbol{\delta}_{\mathbf{4}}(\boldsymbol{j})$ & $\boldsymbol{\delta}_{\mathbf{5}}(\boldsymbol{j})$ \\
\hline 1 & 0 & 0 & 0 & 0 \\
2 & 0 & 0 & 0 & 0 \\
3 & 0.1542 & 0.0617 & 0.0247 & 0.0099 \\
4 & 0.0477 & 0.0191 & 0.0076 & 0.0031 \\
\hline \hline
\end{tabular}

Kemudian pada tahap terminasi digunakan persamaan (7) dan (8), didapatkan hasil sebagai berikut:

$$
\begin{aligned}
P^{*} & =\max \left\{\delta_{5}(1), \delta_{5}(2), \delta_{5}(3), \delta_{5}(4)\right\} \\
& =\max \{0,0,0.0099,0.0031\}=0.0099
\end{aligned}
$$

$X_{5}^{*}=\arg \max \left\{\delta_{5}(1), \delta_{5}(2), \delta_{5}(3), \delta_{5}(4)\right\}=3\left(S_{3}\right)$

Dan tahap terakhir yaitu tahap backtracking. Digunakan persamaan (13) untuk mengetahui barisan keadaan tersembunyi dari lima observasi. Diperoleh barisan indeks close ISSI yang paling optimal untuk pembagian 4 state adalah $X^{*}=\left\{S_{3}, S_{3}, S_{3}, S_{3}, S_{3}\right\}$.

\section{Penaksiran Parameter Model Hidden Markov}

Agar Model Hidden Markov dapat digunakan untuk waktu yang akan datang tanpa menentukan ulang parameter input maka dilakukan penaksiran parameter-parameter Model Hidden Markov yang optimal dari data yang diolah dengan menggunakan algoritma Baum-Welch.

Dengan menggunakan algoritma Baum-Welch dapat dicari penaksir parameter Model Hidden Markov yaitu $\hat{\lambda}=(\hat{A}, \hat{B}, \hat{\pi})$. Penaksir inilah yang nantinya akan mengasilkan $P(O \mid \hat{\lambda}) \geq$ $P(O \mid \lambda)$.

Langkah pertama untuk menaksir parameter Model Hidden Markov yaitu mencari probabilitas proses menggunakan persamaan (14) yaitu:

$$
\xi_{t}(i, j)=\frac{\alpha_{t}(i) a_{i j} b_{j}\left(O_{t+1}\right) \beta_{t+1}(j)}{P(O \mid \lambda)}
$$

Nilai $\xi_{t}(i, j)$ yang dihasilkan untuk pembagian 4 state sebagai berikut:

untuk $t=1$ dan $O_{2}=$ naik

untuk $t=3$ dan $O_{4}=$ naik

Tabel 2.

Peluang Proses pada State $(i, j)$ saat $t=1$

\begin{tabular}{rrrrr}
\hline & 1 & & 3 & \multicolumn{1}{c}{4} \\
\hline 1 & 0 & 0 & 0 & 0 \\
2 & 0 & 0 & 0 & 0 \\
3 & 0 & 0 & 0.5870 & 0.1674 \\
4 & 0 & 0 & 0.1873 & 0.0583 \\
\hline \hline
\end{tabular}

untuk $t=2$ dan $O_{3}=$ naik

Tabel 3.

Peluang Proses pada State $(i, j)$ saat $t=2$

\begin{tabular}{rrrrr}
\hline$i$ & 1 & 2 & 3 & \multicolumn{1}{c}{4} \\
\hline 1 & 0 & 0 & 0 & 0 \\
2 & 0 & 0 & 0 & 0 \\
3 & 0 & 0 & 0.6025 & 0.1718 \\
4 & 0 & 0 & 0.1721 & 0.0535 \\
\hline \hline
\end{tabular}


Tabel 4.

Peluang Proses pada State $(i, j)$ saat $t=3$

\begin{tabular}{rrrrr}
\hline$i$ & 1 & 2 & 3 & \multicolumn{1}{c}{4} \\
\hline 1 & 0 & 0 & 0 & 0 \\
2 & 0 & 0 & 0 & 0 \\
3 & 0 & 0 & 0.6026 & 0.1721 \\
4 & 0 & 0 & 0.1719 & 0.0535 \\
\hline \hline
\end{tabular}

untuk $t=4$ dan $O_{5}=$ naik

Tabel 5.

Peluang Proses pada State $(i, j)$ saat $t=4$

\begin{tabular}{rrrrr}
\hline$i$ & 1 & 2 & 3 & \multicolumn{2}{c}{4} \\
\hline 1 & 0 & 0 & 0 & 0 \\
2 & 0 & 0 & 0 & 0 \\
3 & 0 & 0 & 0.5914 & 0.1831 \\
4 & 0 & 0 & 0.1686 & 0.0569 \\
\hline \hline
\end{tabular}

Dari hasil di atas dicari peluang proses menggunakan persamaan (15) dengan bantuan software MATLAB. Untuk $1 \leq t \leq 4 \quad$ dan $\quad O_{2}=1($ naik $), O_{3}=1($ naik $), O_{4}=$ 1(naik), dan $O_{5}=1$ (naik) diperoleh hasil sebagai berikut:

Tabel 6.

Peluang Proses 4 State

\begin{tabular}{ccccc}
\multicolumn{5}{c}{ Peluang Proses 4 State } \\
\hline \hline$i$ & 1 & 2 & 3 & 4 \\
\hline$\gamma_{1}(i)$ & 0 & 0 & 0.7544 & 0.2456 \\
$\gamma_{2}(i)$ & 0 & 0 & 0.7744 & 0.2256 \\
$\gamma_{3}(i)$ & 0 & 0 & 0.7747 & 0.2253 \\
$\gamma_{4}(i)$ & 0 & 0 & 0.7745 & 0.2255 \\
\hline \hline
\end{tabular}

Kemudian dilakukan penaksiran parameter dengan menggunakan persamaan (16), (17), dan (18). Berikut hasil penghitungan untuk penaksir parameter-parameter Model Hidden Markov:

- Nilai taksiran peluang keadaan awal untuk $t=1$

$$
\hat{\pi}=\left[\begin{array}{llll}
0 & 0 & 0.7544 & 0.2456
\end{array}\right]
$$

- Taksiran matriks transisi

$$
\hat{A}=\left[\begin{array}{cccc}
N a N & N a N & N a N & N a N \\
N a N & N a N & N a N & N a N \\
0 & 0 & 0.7744 & 0.2256 \\
0 & 0 & 0.7591 & 0.2409
\end{array}\right]
$$

- Taksiran matriks emisi

$$
\hat{B}=\left[\begin{array}{cc}
N a N & N a N \\
N a N & N a N \\
1 & 0 \\
1 & 0
\end{array}\right]
$$

\section{GUI Prediksi ISSI Menggunakan Model Hidden Markov}

Untuk mempermudah penghitungan dalam memprediksi indeks saham, dibuat program untuk menghitung nilai prediksi dengan bantuan software MATLAB. Berikut Gambar 2 adalah tampilan dari simulasi prediksi Indeks Saham Syariah Indonesia menggunakan Model Hidden Markov.

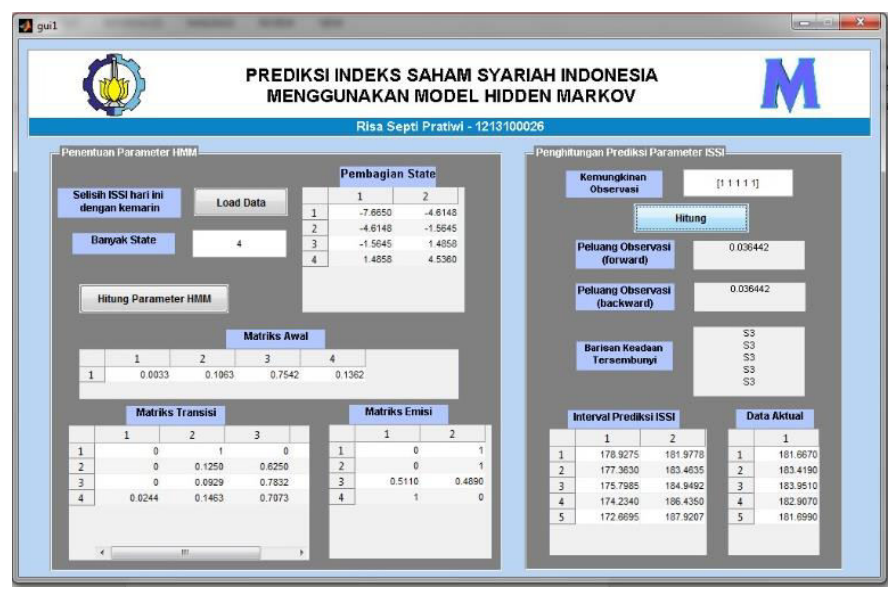

Gambar 2. Tampilan GUI Prediksi Indeks Saham Syariah Indonesia Menggunakan Model Hidden Markov.

\section{Analisis Hasil Simulasi}

Pada bagian ini dijabarkan hasil simulasi yang telah didapatkan. Prediksi indeks penutupan (close index) pada 5 hari berikutnya, yaitu pada bulan April 2017 diperoleh dari penentuan barisan keadaan tersembunyi. Pada pembagian 4 state barisan keadaan tersembunyi yaitu $X^{*}=\left\{S_{3}, S_{3}, S_{3}, S_{3}, S_{3}\right\}$.

Pada hari terakhir pengamatan, indeks saham berada pada nilai 180.492 . Berdasarkan barisan keadaan tersembunyi yang paling optimal, maka prediksi indeks saham hari pertama sampai hari kelima akan mengalami penurunan dan kenaikan sebesar interval $S_{3}$ yaitu [-1.5645, 1.4858). Berikut prediksi indeks saham pada 5 hari berikutnya dibandingkan dengan data aktual.

Tabel 7.

Nilai Prediksi ISSI 4 State

\begin{tabular}{ccc}
\hline \hline Tanggal & Nilai Prediksi & Data Aktual \\
\hline 31 Maret 2017 & & 180.492 \\
3 April 2017 & $78.9275,181.9778)$ & 181.667 \\
4 April 2017 & $77.3630,183.4635)$ & 183.419 \\
5 April 2017 & $75.7985,184.9492)$ & 183.951 \\
6 April 2017 & $74.2340,186.4350)$ & 182.907 \\
7 April 2017 & $72.6695,187.9207)$ & 181.699 \\
\hline \hline
\end{tabular}

Dari kelima nilai prediksi, semua data aktual berada dalam range nilai prediksi. Jadi nilai akurasi prediksi dengan pembagian 4 state sebesar $100 \%$.

Pada pembagian 3 state peluang observasi terbesar yang diperoleh adalah 0.0412 yaitu barisan observasi $O=$ (naik,naik,naik,naik,naik) dan barisan keadaan tersembunyi yaitu $X^{*}=\left\{S_{3}, S_{3}, S_{3}, S_{3}, S_{3}\right\}$. Dari kelima nilai prediksi, terdapat satu data aktual yang berada di luar range nilai prediksi yaitu pada hari kelima. Jadi nilai akurasi prediksi dengan pembagian 3 state sebesar $\frac{4}{5} \times 100 \%=80 \%$.

Pada pembagian 5 state peluang observasi terbesar yang diperoleh adalah 0.0412 yaitu barisan observasi $O=$ (naik,naik,naik,naik,naik) dan barisan keadaan 
tersembunyi yaitu $X^{*}=\left\{S_{4}, S_{4}, S_{4}, S_{4}, S_{4}\right\}$. Dari kelima nilai prediksi, semua data aktual berada dalam range nilai prediksi. Jadi nilai akurasi prediksi dengan pembagian 5 state sebesar $100 \%$.

Pada pembagian 6 state peluang observasi terbesar yang diperoleh adalah 0.0398 yaitu barisan observasi $O=$ (naik,naik,naik, naik, naik) dan barisan keadaan tersembunyi yaitu $X^{*}=\left\{S_{5}, S_{5}, S_{5}, S_{5}, S_{5}\right\}$. Dari kelima nilai prediksi, terdapat satu data aktual yang berada di luar range nilai prediksi yaitu pada hari kelima. Jadi nilai akurasi prediksi dengan pembagian 6 state sebesar $\frac{4}{5} \times 100 \%=80 \%$.

Kemudian pada pembagian 7 state diperoleh matriks peluang transisi

$A=\left[\begin{array}{ccccccc}0 & 0 & 1 & 0 & 0 & 0 & 0 \\ N a N & N a N & N a N & N a N & N a N & N a N & N a N \\ 0 & 0 & 0.1667 & 0.1667 & 0.2500 & 0.2500 & 0.1667 \\ 0 & 0 & 0.0455 & 0.1970 & 0.5152 & 0.1970 & 0.0455 \\ 0 & 0 & 0.0261 & 0.2353 & 0.5163 & 0.1961 & 0.0261 \\ 0.0182 & 0 & 0.0364 & 0.2000 & 0.5455 & 0.1455 & 0.0545 \\ 0 & 0 & 0 & 0.3077 & 0.5385 & 0.0769 & 0.0769\end{array}\right]$

dan pada pembagian 8 state diperoleh matriks peluang transisi

$$
A=\left[\begin{array}{cccccccc}
0 & 0 & 1 & 0 & 0 & 0 & 0 & 0 \\
N a N & N a N & N a N & N a N & N a N & N a N & N a N & N a N \\
0 & 0 & 0 & 0.5000 & 0 & 0.5000 & 0 & 0 \\
0 & 0 & 0 & 0.1000 & 0.2667 & 0.3667 & 0.1333 & 0.1333 \\
0 & 0 & 0 & 0.1048 & 0.4190 & 0.3524 & 0.1143 & 0.0095 \\
0 & 0 & 0.0083 & 0.0744 & 0.3388 & 0.4545 & 0.1157 & 0.0083 \\
0.0323 & 0 & 0 & 0.1613 & 0.2581 & 0.4194 & 0.0323 & 0.0968 \\
0 & 0 & 0 & 0.1000 & 0.5000 & 0.3000 & 0 & 0.1000
\end{array}\right]
$$

Matriks peluang transisi pada state 2 bernilai $N a N$ untuk masing-masing pembagian 7 state dan 8 state. Hal ini karena elemen dari state 2 kosong (tidak mempunyai anggota) sehingga tidak memenuhi karakteristik Model Hidden Markov yaitu untuk setiap $\sum_{j=1}^{N} a_{i j}=1$. Jadi prediksi ISSI hanya dilakukan sampai 6 state.

\section{KESIMPULAN}

Berdasarkan hasil analisis dan pembahasan yang telah disajikan pada bab sebelumnya, dapat diambil kesimpulan sebagai berikut:

1. Model Hidden Markov dapat digunakan untuk memprediksi data Indeks Saham Syariah Indonesia dengan pembagian 3, 4, 5, dan 6 state. Prediksi ISSI hanya dapat dilakukan sampai 6 state, karena pada pembagian 7 dan 8 state tidak memenuhi karakteristik Model Hidden Markov.

2. Pada pembagian $3,4,5$, dan 6 state diperoleh peluang terbesar pada observasi $O=$ (naik, naik, naik, naik, naik). Nilai prediksi ISSI merupakan jumlahan dari indeks saham pada hari sebelumnya dengan interval state pada barisan keadaan tersembunyi. Barisan keadaan tersembunyi pada pembagian 3 state adalah $X^{*}=\left\{S_{3}, S_{3}, S_{3}, S_{3}, S_{3}\right\}$, pada pembagian 4 state adalah $X^{*}=\left\{S_{3}, S_{3}, S_{3}, S_{3}, S_{3}\right\}$, pada pembagian 5 state adalah $X^{*}=\left\{S_{4}, S_{4}, S_{4}, S_{4}, S_{4}\right\}$, dan pada pembagian 6 state adalah $X^{*}=\left\{S_{5}, S_{5}, S_{5}, S_{5}, S_{5}\right\}$.

3. Keakuratan hasil prediksi dilihat dengan membandingkan range nilai prediksi dengan data aktual. Pada pembagian 4 dan 5 state, nilai prediksi memiliki kecocokan $100 \%$. Sedangkan pada pembagian 3 dan 6 state terdapat satu data aktual yang berada di luar range nilai prediksi, sehingga tingkat kecocokannya sebesar $80 \%$.

\section{DAFTAR PUSTAKA}

[1] Y. Respati, “Apa Itu Indeks Saham Syariah Indonesia?”. Berita Ekonomi \& Keuangan Syariah," 2015. [Online]. Available: http://keuangansyariah.mysharing.co/apa-itu-indeks-saham-syariahindonesia/.

[2] M. Zulfikar and et al, "Implementasi Hidden Markov Model pada Peramalan Data Saham,” J. Progr. Stud. Sarj. Stat., 2016.

[3] Z. Ghahramani, "An Introduction Hidden Markov Models and Bayesian Network," Int. J. Pattern Recognit. Artifizial Intell., 2001.

[4] V. D. Fonzo, F. A. Pentini, and V. Parisi, Hidden Markov Models in Bioinformatics. Bentham Science Publishers Ltd., 2007.

[5] L. R. Rabiner, "A Tutorial on Hidden Markov Models and Seleted Applications in Speech Recognition," in Proceeding Of The IEEE, 1989. 